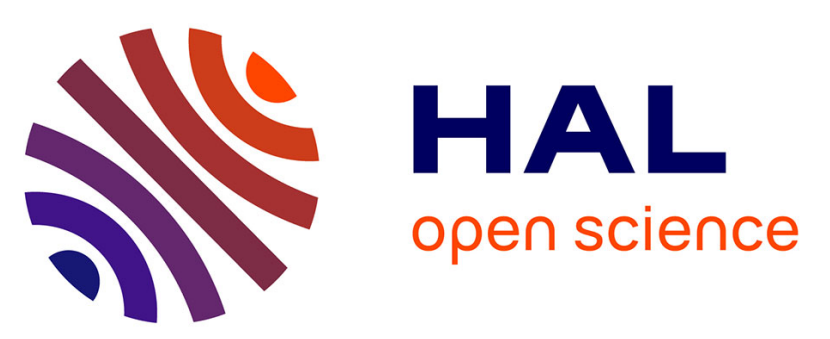

\title{
A dual-plate ITO-ITO generator-collector microtrench sensor: surface activation, spatial separation and suppression of irreversible oxygen and ascorbate interference
}

Mohammad A. Hasnat, Andrew James Gross, Sara E. Dale, Edward O. Barnes, Richard G. Compton, Frank Marken

\section{To cite this version:}

Mohammad A. Hasnat, Andrew James Gross, Sara E. Dale, Edward O. Barnes, Richard G. Compton, et al.. A dual-plate ITO-ITO generator-collector microtrench sensor: surface activation, spatial separation and suppression of irreversible oxygen and ascorbate interference. Analyst, 2014, 139 (3), pp.569-575. 10.1039/C3AN01826A . hal-03015200

\author{
HAL Id: hal-03015200 \\ https://hal.science/hal-03015200
}

Submitted on 19 Nov 2020

HAL is a multi-disciplinary open access archive for the deposit and dissemination of scientific research documents, whether they are published or not. The documents may come from teaching and research institutions in France or abroad, or from public or private research centers.
L'archive ouverte pluridisciplinaire $\mathbf{H A L}$, est destinée au dépôt et à la diffusion de documents scientifiques de niveau recherche, publiés ou non, émanant des établissements d'enseignement et de recherche français ou étrangers, des laboratoires publics ou privés. 


\title{
Revision
}

$8^{\text {th }}$ November 2013

\section{A Dual-Plate ITO-ITO Generator-Collector Microtrench Sensor: Surface Activation, Spatial Separation and Suppression of Irreversible Oxygen and Ascorbate Interferences}

\author{
Mohammad A. Hasnat ${ }^{\mathrm{a}, \mathrm{b}}$, Andrew J. Gross ${ }^{\mathrm{b}}$, Sara E.C. Dale ${ }^{\mathrm{b}}$, Edward O. Barnes ${ }^{\mathrm{c}}$, \\ Richard G. Compton ${ }^{\mathrm{c}}$, and Frank Marken ${ }^{\mathrm{b} *}$ \\ ${ }^{a}$ Department of Chemistry, Graduate School of Physical Sciences, Shahajalal \\ University of Science and Technology, Sylhet-3114, Bangladesh \\ ${ }^{b}$ Department of Chemistry, University of Bath, Bath BA2 7AY, UK \\ ${ }^{c}$ Department of Chemistry, Physical and Theoretical Chemistry Laboratory, Oxford \\ University, South Parks Road, Oxford OX1 3QZ, UK
}

To be submitted to The Analyst

Proofs to F. Marken

F.Marken@bath.ac.uk 


\begin{abstract}
Generator-collector electrode systems are based on two independent working electrodes with overlapping diffusion fields where chemically reversible redox processes (oxidation and reduction) are coupled to give amplified current signals. A generator-collector trench electrode system prepared from two tin-doped indium oxide (ITO) electrodes placed vis-à-vis with $22 \mu \mathrm{m}$ inter-electrode gap is employed here as a sensor in aqueous media. The reversible 2-electron anthraquinone-2sulfonate redox system is demonstrated to give well-defined collector responses even in the presence of oxygen due to irreversible nature of the oxygen reduction. For the oxidation of dopamine on ITO, novel "Piranha-activation" effects are observed and chemically reversible generator-collector feedback conditions are achieved at $\mathrm{pH} 7$, by selecting a more negative collector potential, again eliminating possible oxygen interference. Finally, dopamine oxidation in the presence of ascorbate is demonstrated with the irreversible oxidation of ascorbate at the "mouth" of the trench electrode and chemically reversible oxidation of dopamine in the trench "interior". This spatial separation of chemically reversible and irreversible processes within and outside the trench is discussed as a potential in situ microscale sensing and separation tool.
\end{abstract}

Keywords: dopamine, ascorbate, oxygen, interference, electroanalysis, sensors. 


\section{Introduction}

New types of electrochemical sensor electrodes are desirable, in particular for applications in complex media and multi-analyte cases, ${ }^{1}$ for example, in blood analysis., ${ }^{2,3}$ Electrochemical methods are attractive as they often allow rapid on-site or point-of-care measurements without the need for separation or off-line laboratory apparatus. Sensitivity and selectivity of electrodes as well as multi-purpose analysis applications are of interest.

Recently, the benefits of "junction electrode systems", with generator-collector" ${ }^{5,6}$ or modulator-sensor ${ }^{7}$ electrode arrangements under bipotentiostatic control have been highlighted. In the extreme limit, as dual-plate nano-gap sensors, ${ }^{8}$ these kinds of electrode systems can be employed down to single molecule sensitivity ${ }^{9}$ and with the opportunity for novel statistical analysis techniques being developed. ${ }^{10}$ More generally, the generator-collector configuration with bipotentiostatic control offers benefits due to (i) the steady state nature of analytical responses, (ii) the amplification effect, which is inversely proportional to the inter-electrode gap $\delta$ (in first approximation $\left.^{11,12}\right) I_{\text {feedback }}=\frac{n D F A c}{\delta}$ with $n$, the number of electrons transferred per molecule diffusing to the electrode, $D$ the diffusion coefficient, $F$ the Faraday constant, $A$ the area, and $c$ the concentration), and (iii) the possibility to fill the trench with a "filter" or "separation" material such as cellulose. ${ }^{13}$ A particularly useful sensor geometry is the dual-plate or "trench" electrode system which was initially developed, reported, and treated by Sluyters, ${ }^{14}$ Anson, ${ }^{15}$ Reilley, ${ }^{16}$ and Hubbard,${ }^{17}$ and more recently employed in electroanalysis. ${ }^{18,19}$ Here, further benefits of this type of 
electrode system where separated trench "interior" and "mouth" regions can be assigned (see red and green regions in Figure 1C, respectively) are identified in terms of suppression of interference responses and effects.
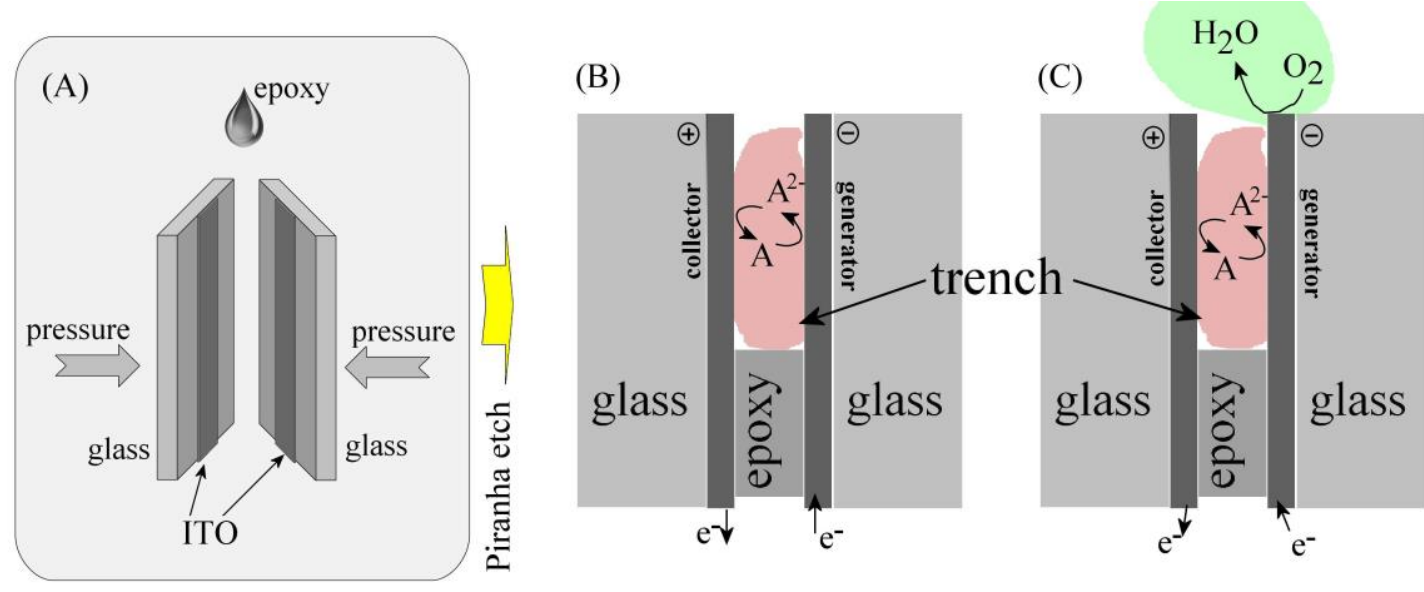

Figure 1. Schematic drawing of (A) the assembly of the ITO-ITO dual-plate trench electrode system, (B) the operation in generator-collector feedback mode for amplified detection of a chemically reversible redox system, and (C) the "exclusion" of the irreversible redox system (e.g. $\mathrm{O}_{2}$ reduction) from the trench region. The green region is the "mouth" region and the red region is the "interior" region.

In this report it is demonstrated that ITO-ITO dual-plate electrode systems assembled by placing a thin layer of epoxy between two ITO electrodes (see Figure 1A) can be employed in electroanalytical tasks where interferences from oxygen or other chemically irreversible redox active reagents traditionally cause problems. With two active electrodes, the generator and the collector, one electrode can be polarized to actively remove chemically irreversible redox systems, such as $\mathrm{O}_{2}$ or ascorbate, from the "trench" region of the dual-plate electrode system. As a result, the collector limiting current reading becomes insensitive to the interfering species. In fact, the 
interfering species can be essentially removed from the inter-electrode or "trench" region with potential future applications in nanoscale in situ separation and detection.

The redox systems selected for this study are the two-electron reduction of anthraquinone and the two-electron oxidation of dopamine ${ }^{20}$ to reflect possible problems of interferences during reduction (oxygen) and interferences during oxidation (ascorbate). Both of these systems have been studied for a considerable time. The reduction of anthraquinones is important as redox mediators ${ }^{21}$ and in particular in the catalytic reduction of oxygen to hydrogen peroxide. ${ }^{22}$ The oxidation of dopamine has been studied particularly for in vivo application where signaling mechanisms between cells are investigated. ${ }^{23,24}$

Although methods reported in this study cannot compete with the wide range of existing methods ${ }^{25}$ and with the exquisite sub-micro-molar sensitivity achieved for example by graphene-based electrodes, ${ }^{26}$ the ongoing development of new generatorcollector sensing tools ${ }^{27}$ could be fruitful with both potential for high sensitivity and for suppression of interferences in improved devices. A recent study of the geometry effects for generator-collector sensors for dopamine (in the presence of ascorbate) has highlighted important advantages. ${ }^{28}$

\section{Experimental}

\subsection{Chemical Reagents}

Anthraquinone-2-sulfonic acid sodium salt monohydrate (97\%), L-ascorbic acid (99 $\%$ ), dopamine hydrochloride, sodium hydroxide ( $\geq 98 \%$ ), phosphoric acid, nitric acid 
( $\geq 69 \%$ ), hydrogen peroxide (30 wt. \% in water), sulphuric acid (95 - 98\%), oxalic acid (98\%) and tartaric acid (99.5\%) were all purchased from Sigma Aldrich (UK). Aqueous solutions were made with Barnstead Nanopure water (>18.2 $\mathrm{M} \Omega \mathrm{cm}$ at 20 $\left.{ }^{\circ} \mathrm{C}\right)$. Nitrogen (BOC) was employed to de-aerate electrolyte solutions. Experiments were conducted at $20 \pm 2{ }^{\circ} \mathrm{C}$.

\subsection{Instrumentation}

Electrochemical measurements were performed using either a PGSTAT12 biopotentiostat system (Autolab, EcoChemie, Netherlands) with GPES 4.7 software or a CompactStat with bipotentiostat module (Ivium Technologies, Netherlands) with IviumSoft software 2.178. A conventional three or four-electrode cell was employed with a Pt wire counter electrode and $\mathrm{Ag} / \mathrm{AgCl}$ (saturated $\mathrm{KCl}$ ) reference electrode (Radiometer). The three-electrode cell employed an ITO glass slide as the working electrode. The four-electrode cell set-up employed an ITO-ITO junction system with generator and collector working electrodes. Scanning electron microscopy (SEM) micrographs were recorded using a JSM-6480LV (JEOL, Japan). A $5 \mathrm{~nm}$ layer of chromium was sputter deposited onto the substrate prior to SEM analysis.

\subsection{Electrode Fabrication}

Tin-doped indium oxide junction electrodes were prepared following a method described previously. ${ }^{16}$ Briefly, ITO glass slides (Image Optics, Basildon, UK) were cut into $10 \mathrm{~mm} \times 25 \mathrm{~mm}$ substrates then masked using Kapton tape (Farnell) to give a masked strip in the centre of the electrode $(5 \mathrm{~mm} \times 25 \mathrm{~mm})$. The exposed ITO was then etched using a solution of $1 \mathrm{wt} . \%$ tartaric acid and $3 \mathrm{wt} . \%$ oxalic acid at $35{ }^{\circ} \mathrm{C}$ 
for $20 \mathrm{~min}$. After rinsing and drying, the Kapton tape was removed and the two ITO slides were aligned face-to-face and glued under pressure using epoxy (SP106 multipurpose epoxy, SP Gurit). After curing, the end of the ITO-ITO electrode was removed using a diamond cutter and the freshly exposed surface subsequently polished flat using SiC paper (P320, Buehler). The epoxy in between the ITO-ITO electrode was etched out using Piranha solution (1:5 hydrogen peroxide: sulphuric acid; WARNING: this solution is highly aggressive) to yield the micro-trench junction electrode (see Figure 2). Piranha solution treatment was also applied to clean micro-trench electrodes as well as bare ITO electrodes (see text) used in voltammetric measurements.
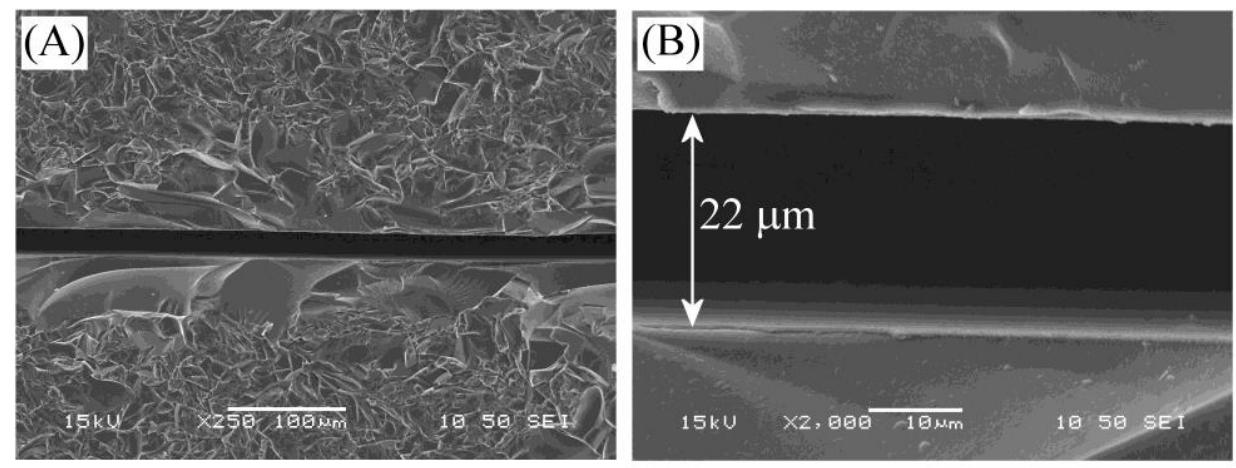

Figure 2. SEM images of the ITO-ITO dual-plate trench electrode system at (A) low and (B) high magnification (The electrode was sputter-coated with chromium prior to imaging).

\section{Results and Discussion}

\subsection{Dual-Plate Microgap Sensor Electroanalysis I.: Reduction of Anthraquinone-}

\section{2-sulfonate in Aqueous 0.1 $\mathrm{M} \mathrm{NaOH}$}


The electrochemical reduction of anthraquinone-2-sulfonate occurs in a 2-electron multi-step mechanism ${ }^{29}$ with cation association exerting strong effects on the reversible potential ${ }^{30}$ of the electron transfer in step 1 (equation 1a) and in step 2 (equation $1 b)$.

$$
\begin{aligned}
& \mathrm{AQ}(\mathrm{aq})+\mathrm{e}^{-} \rightleftarrows \mathrm{AQ}^{-}(\mathrm{aq}) \\
& \mathrm{AQ}^{-}(\mathrm{aq})+\mathrm{e}^{-} \rightleftarrows \mathrm{AQ}^{2-}(\mathrm{aq})
\end{aligned}
$$

In aqueous $0.1 \mathrm{M} \mathrm{NaOH}$ both reduction responses should merge into a single 2electron reduction which is observed at $-0.56 \mathrm{~V}$ vs. $\mathrm{Ag} / \mathrm{AgCl}$. However, at ITO electrodes further complexity is induced by the presence of oxygen in the electrolyte solution (see Figure 3).

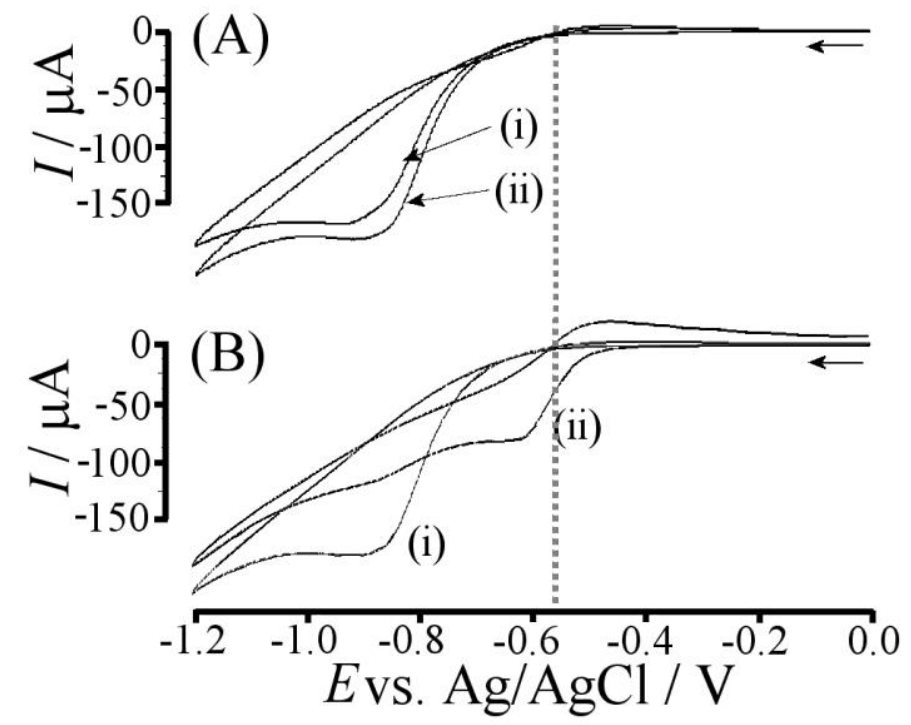

Figure 3. (A) Cyclic voltammograms (scan rate $0.1 \mathrm{Vs}^{-1}$ ) for the reduction of $100 \mu \mathrm{M}$ anthraquinone-2-sulfonate in $0.1 \mathrm{M} \mathrm{NaOH}$ at a $1 \mathrm{~cm}^{2}$ ITO electrode for (i) a bare ITO electrode and (ii) a Piranha-treated ITO electrode. (B) As above but with (i) oxygen present and (ii) argon atmosphere. A dashed line indicates the approximate reversible potential. 
The anthraquinone-2-sulfonate reduction is affected by the presence of oxygen in solution which, in particular at low anthraquinone-2-sulfonate concentration, causes a significant increase in current (and the formation of peroxide ${ }^{31,32}$ ). The expected reversible reduction of anthraquinone-2-sulfonate is observed only after de-aeration (see Figure 3B) with a second reduction peak at more negative potentials (ca. $-0.85 \mathrm{~V}$ vs. $\mathrm{Ag} / \mathrm{AgCl}$ ) dominating all data obtained in the presence of oxygen. The change in reactivity when treating the ITO electrode surface with Piranha solution is insignificant. The negative shift in potential and irreversibility of the voltammetric response for anthraquinone-2-sulfonate reduction in the presence of oxygen may be associated with the formation of an oxygen adduct of the reduced anthraquinone species. However, further mechanistic details of this process are beyond the scope of this study.

Perhaps surprisingly, a considerable change in voltammetric behaviour is observed when using the dual-plate electrode in the presence of oxygen. Data obtained with a dual-plate ITO-ITO micro-trench electrode with $22 \mu \mathrm{m}$ inter-electrode gap (see Figure 2) is shown in Figure 4. Well-defined steady-state mass transport limited currents at the reversible potential are observed (even in the presence of oxygen), which reflect a fully active trench electrode area as long as both the generator and the collector electrode are set to sufficiently positive and negative potentials (relative to the reversible potential). 

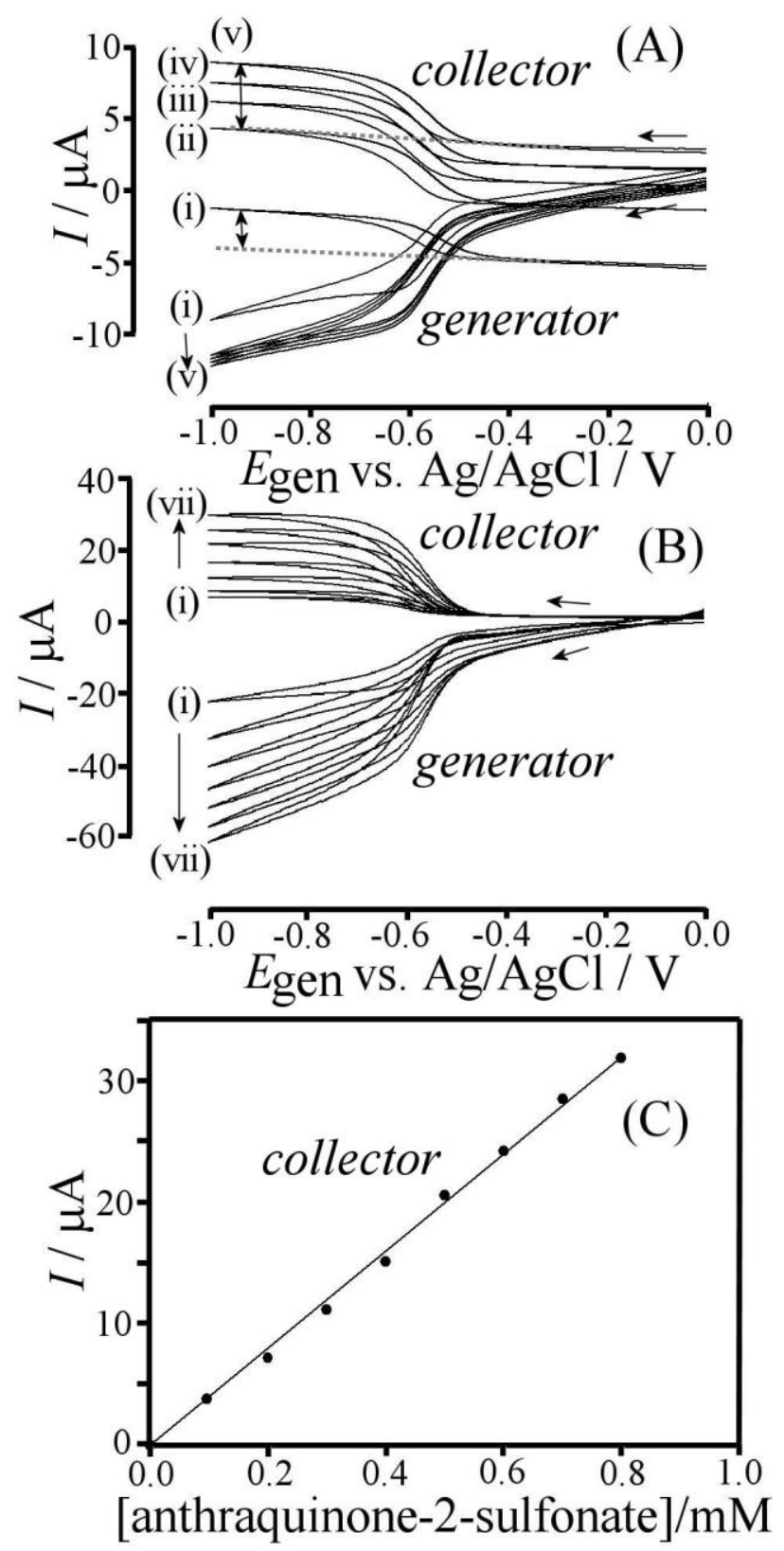

Figure 4. (A) Generator-collector cyclic voltammograms (scan rate $0.025 \mathrm{Vs}^{-1}$, $\mathrm{E}_{\text {collector }}=$ (i) -0.5 , (ii) -0.25 , (iii) 0.0 , (iv) 0.25 , and (v) $0.5 \mathrm{~V}$ vs. $\mathrm{Ag} / \mathrm{AgCl}$ ) for the reduction of $100 \mu \mathrm{M}$ anthraquinone-2-sulfonate in aqueous $0.1 \mathrm{M} \mathrm{NaOH}$. (B) As above with $\mathrm{E}_{\text {collector }}=0.5 \mathrm{~V}$ vs. $\mathrm{Ag} / \mathrm{AgCl}$ and [anthraquinone-2-sulfonate] = (i) 0.1 , (ii) 0.2 , (iii) 0.3 , (iv) 0.4 , (v) 0.5 , (vi) 0.6 , and (vii) $0.7 \mathrm{mM}$. (C) Plot of the collector limiting current versus concentration.

Data in Figure 4A demonstrates the generator and collector currents for an anthraquinone-2-sulfonate concentration of $100 \mu \mathrm{M}$. The generator limiting current exhibits a drifting baseline, however, the collector limiting current is well-defined 
(apart from a shift in baseline current) and a precise analytical reading is possible (see dashed line in $4 \mathrm{Ai}$ and $4 \mathrm{Av}$ ) even in the presence of oxygen in bulk solution. Changing the applied collector potential does not significantly change the collector limiting current (except for collector potential settings close to the reversible potential, see 4Ai), but it does shift the collector response due to oxygen background processes (outside of the trench region, vide infra). Data in Figure $4 \mathrm{~B}$ and $4 \mathrm{C}$ demonstrate a linear dependence of collector limiting current on concentration. The hysteresis effect of ca. $54 \mathrm{mV}$ in the collector current response at a scan rate of 25 $\mathrm{mVs}^{-1}$ is consistent with diffusional delay across the inter-electrode gap. The diffusion coefficient for anthraquinone-2-sulfonate under similar experimental conditions has been reported as $D_{\text {anthraquinone-2-sulfonate }}=5.7 \times 10^{-9} \mathrm{~m}^{2} \mathrm{~s}^{-1} \cdot{ }^{18}$ With the diffusion coefficient for anthraquinone-2-sulfonate known, and with the inter-electrode gap determined as $22 \mu \mathrm{m}$ (see Experimental, Figure 2), the average trench depth can be estimated (see equation 2, this equation is appropriate here and consistent with work by Reilley ${ }^{16}$ and Hubbard ${ }^{17}$ ).

$$
\text { Trench depth }=\frac{I_{\text {lim }} \times \delta}{n F D w c}=800 \mu \mathrm{m}
$$

Here $I_{\lim }$ is the limiting current and $w$ denotes the width of the trench electrode. The sensor therefore has an aspect ratio of approximately 36. In summary, the reduction and back-oxidation of anthraquinone-2-sulfonate at the ITO-ITO dual-plate electrode occurs with good sensitivity and without interference from oxygen in the solution phase presumably due to "pre-electrolysis" (irreversible removal of oxygen at the generator electrode) at the "mouth" of the dual-plate trench electrode (see Figure 1C). 


\subsection{Dual-Plate Microgap Sensor Electroanalysis II.: Oxidation of Dopamine in}

\section{Aqueous Phosphate Buffer $\mathrm{pH} 7$}

The detection of dopamine in the presence of interferences/co-analytes such as ascorbate, ${ }^{33}$ ureate, ${ }^{34}$ and serotonin ${ }^{35}$ has been thoroughly studied for application in the investigation of neuron communication ${ }^{36}$ and detection in urine. ${ }^{37}$ Amplification of the voltammetric signal based on modified electrodes ${ }^{38,39}$ and on dopamine capture and surface derivatisation has been proposed. ${ }^{40}$ Here, dopamine is employed as a model analyte with ascorbate interference to demonstrate the potential benefits of dual-plate trench electrodes in analysis. Very recently Amatore and coworkers also highlighted the importance of geometry effects in generator - collector sensing for the case of dopamine in the presence of ascorbate. ${ }^{41}$

The electrochemistry of dopamine is dominated by the redox active catechol fraction of the molecule. In aqueous buffer media at $\mathrm{pH} 7$ dopamine is present as a cation of overall +1 charge $\left(\mathrm{pK}_{\mathrm{A} 1}=8.9\right.$ and $\left.\mathrm{pK}_{\mathrm{A} 2}=10.4^{42}\right)$ which is oxidised initially in a 2electron process to the 1,2 -dione. ${ }^{43}$ More complex follow-up reactions are known to occur in alkaline media to give dopachrome ${ }^{44}$ (cyclisation and further oxidation) but these are beyond the scope of this study and not relevant for the case of fast interelectrode diffusion (with $\tau \approx \delta^{2} / D$ here approximately $0.48 \mathrm{~s}$ ). 

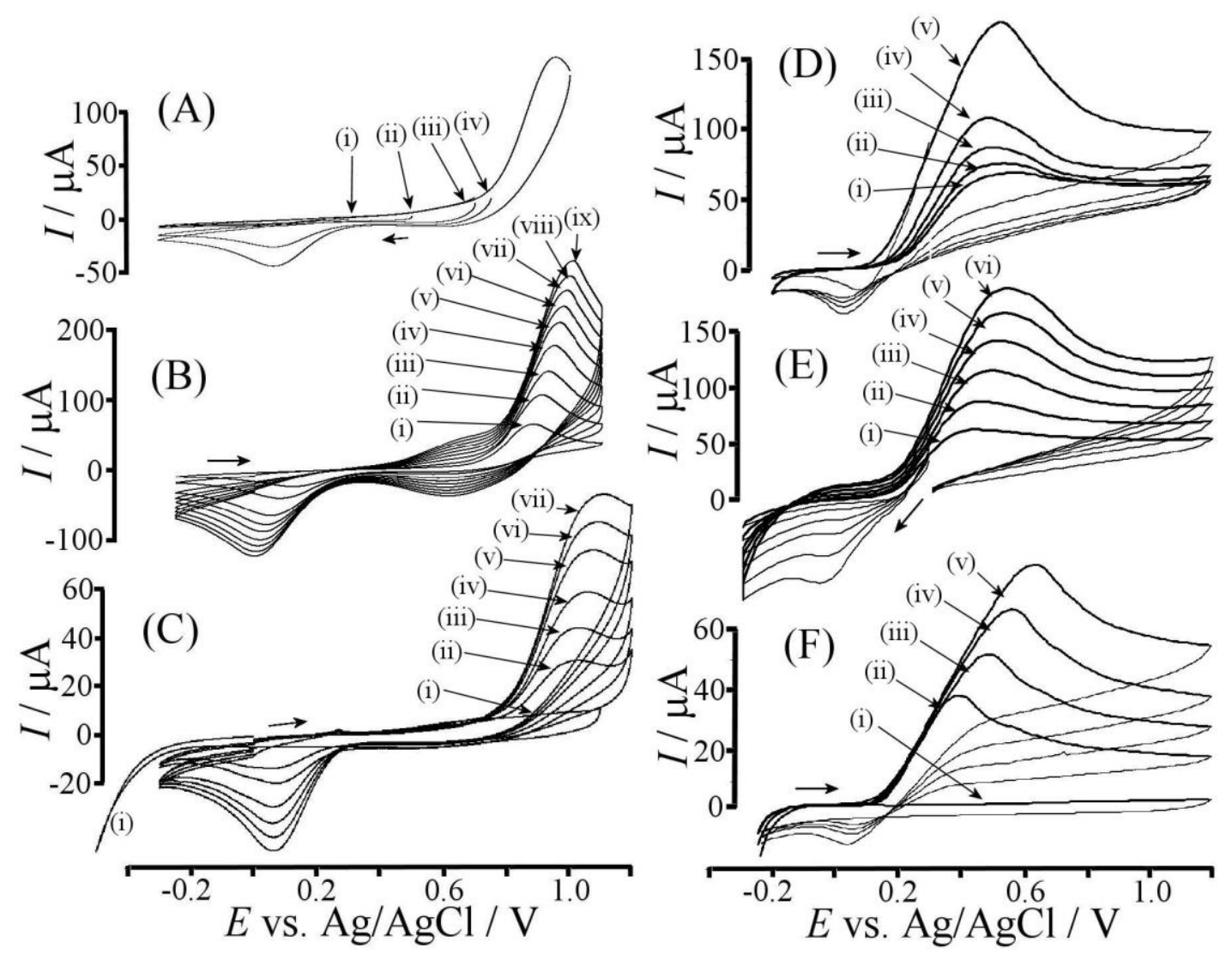

Figure 5. (A) Cyclic voltammograms (scan rate $0.025 \mathrm{Vs}^{-1}$ ) for the oxidation of $1 \mathrm{mM}$ dopamine at a $1 \mathrm{~cm}^{2}$ ITO electrode immersed in $0.1 \mathrm{M}$ phosphate buffer $\mathrm{pH} 7$ with (i) to (iv) indicating different start potentials. (B) As in A, but for scan rates (i) 10, (ii) 25, (iii) 50, (iv) 75 , (v) 100 , (vi) 125 , (vii) 150 , (viii) 175 , and (ix) $200 \mathrm{mVs}^{-1}$. (C) As in $\mathrm{A}$, with scan rate $0.025 \mathrm{Vs}^{-1}$ and for [dopamine] $=$ (i) 0 , (ii) 0.2 , (iii) 0.3 , (iv) 0.4 , (v) 0.5 , (vi) 0.6 , and (vii) $0.7 \mathrm{mM}$. (D) Cyclic voltammograms (scan rate $0.025 \mathrm{Vs}^{-1}$, first 5 potential cycles) for the oxidation of $1 \mathrm{mM}$ dopamine at a $1 \mathrm{~cm}^{2}$ "Piranhaactivated" ITO electrode immersed in $0.1 \mathrm{M}$ phosphate buffer $\mathrm{pH}$ 7. (E) As in D, but for scan rates (i) 10 , (ii) 25 , (iii) 50 , (iv) 75 , (v) 100 , and (vi) $125 \mathrm{mVs}^{-1}$. (F) As in D with scan rate $0.025 \mathrm{Vs}^{-1}$ and for [dopamine] = (i) 0 , (ii) 0.2 , (iii) 0.3 , (iv) 0.4 , and (v) $0.5 \mathrm{mM}$.

Figure 5A shows cyclic voltammograms for $1 \mathrm{mM}$ dopamine in $0.1 \mathrm{M}$ phosphate buffer $\mathrm{pH} 7$ at a $1 \mathrm{~cm}^{2}$ ITO electrode. The oxidation response at $0.95 \mathrm{~V}$ vs. $\mathrm{Ag} / \mathrm{AgCl}$ is shown to be chemically linked to the reduction process at $0.08 \mathrm{~V}$ vs. $\mathrm{Ag} / \mathrm{AgCl}$. The considerable gap between oxidation and back-reduction peak is observed due to the bare ITO surface not being kinetically active rather than formation of follow-up 
chemical products. This changes dramatically when a Piranha cleaning treatment is applied (see experimental). The effect of Piranha treatment on ITO surface roughness and an increase in surface energy have been reported by Vacca et al. ${ }^{45}$ However, effects observed here of Piranha treatment on the electron transfer to dopamine are new. Figure 5D has been obtained under otherwise identical conditions and a change in onset potential (improved electrochemical reversibility) is clearly evident. When changing the scan rate (see Figure 5B), on bare ITO an additional surface immobilised redox system emerges (at higher scan rate) with midpoint potential $0.62 \mathrm{~V}$ vs. $\mathrm{Ag} / \mathrm{AgCl}$. This is assigned tentatively to surface immobilised (physically or chemically) dopamine on the ITO electrode surface. For a Piranha treated ITO electrode, the separation between oxidation and reduction responses appears much less pronounced (Figure 5E). Figure $5 \mathrm{C}$ and $5 \mathrm{~F}$ demonstrate the effect of the dopamine concentration on the oxidation and back-reduction peak responses on bare ITO and on Piranha-treated ITO, respectively.

Next, generator-collector processes in the ITO-ITO dual-plate electrode system were investigated. Figure 6A shows cyclic voltammetry data for $0.25 \mathrm{mM}$ dopamine. The oxidation is observed at the generator electrode with a midpoint potential of ca. 0.25 V vs. $\mathrm{Ag} / \mathrm{AgCl}$, consistent with a Piranha-activated ITO electrode surface. When the collector potential is set to a potential positive of $0.0 \mathrm{~V}$ vs. $\mathrm{Ag} / \mathrm{AgCl}$, only insignificant collection efficiencies are observed. Well-defined collector current responses are obtained for $E_{\text {collector }}=-0.5 \mathrm{~V}$ vs. $\mathrm{Ag} / \mathrm{AgCl}$. The collector current of ca. $5 \mu \mathrm{A}$ is in good agreement with the theoretical value of $I_{\text {lim }}=\frac{n F D A c}{\delta}=5.2 \mu \mathrm{A}$ (with $n=2, D_{\text {dopamine }}=0.6 \times 10^{-9} \mathrm{~m}^{2} \mathrm{~s}^{-1},{ }^{46,47} A=800 \mu \mathrm{m} \times 5 \mathrm{~mm}$, and $\delta=22 \mu \mathrm{m}$, see equation 2). Concentration measurements with optimised collector potential settings 
are possible into the lower $\mu \mathrm{M}$ range (see Figure $6 \mathrm{~B}$ ). These measurements were performed without de-aerating the solution. The removal of oxygen occurs in this case at the collector electrode. In order to explore the effects of other interferences with chemically irreversible electrode reaction the addition of ascorbate was investigated next.
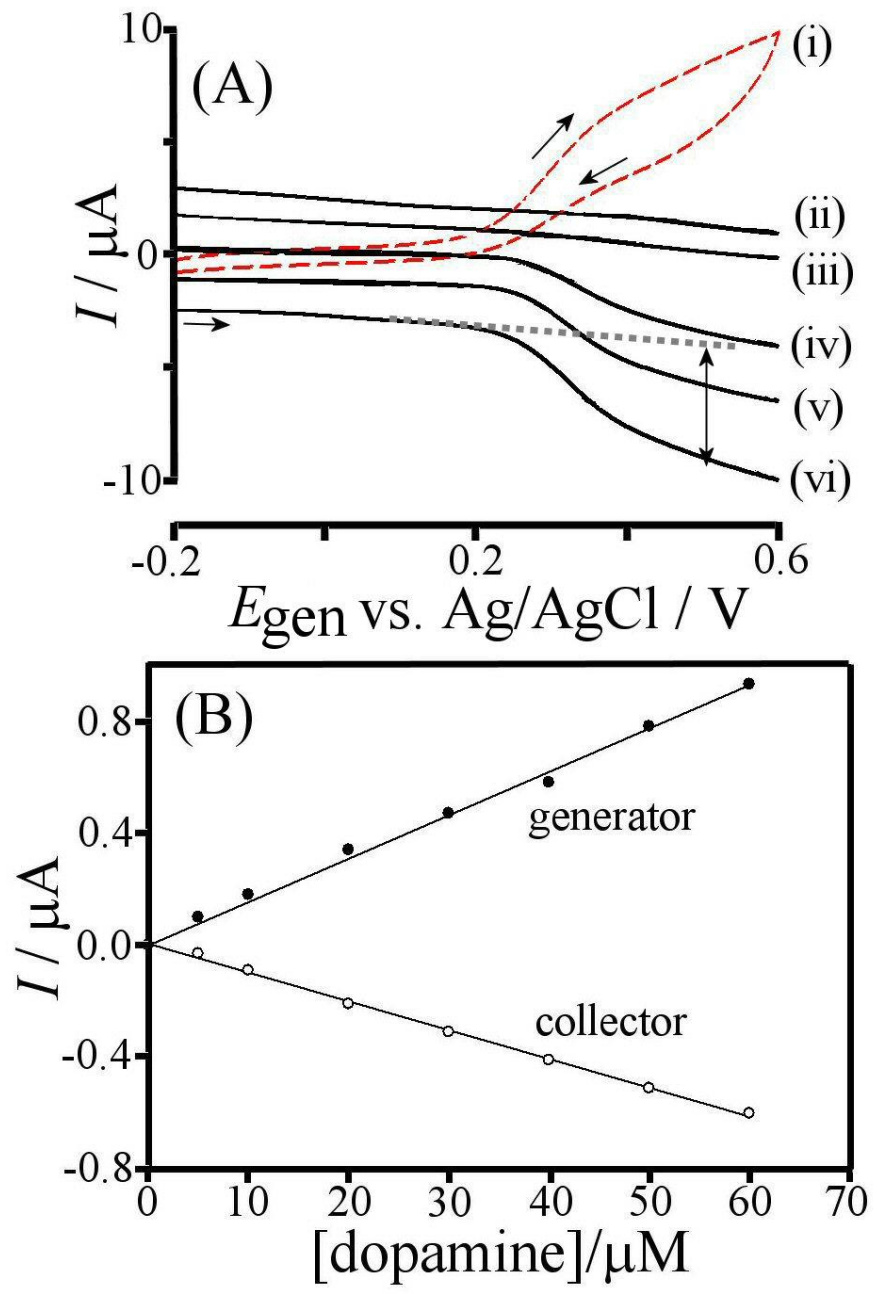

Figure 6. (A) Cyclic voltammograms (scan rate $0.025 \mathrm{Vs}^{-1}$ ) for the oxidation of 0.25 $\mathrm{mM}$ dopamine at a dual-plate ITO-ITO electrode immersed into $0.1 \mathrm{M}$ phosphate buffer $\mathrm{pH}$ 7. The generator current is shown and collector responses for $E_{\text {collector }}=$ (ii) 0.5, (iii) 0.25 , (iv) 0.0 , (v) -0.25 , and (vi) $-0.5 \mathrm{~V}$ vs. $\mathrm{Ag} / \mathrm{AgCl}$. (B) Plot of the generator and collector limiting currents as a function of dopamine concentration recorded with $E_{\text {collector }}=-0.5 \mathrm{~V}$ vs. $\mathrm{Ag} / \mathrm{AgCl}$. 


\subsection{Dual-Plate Microgap Sensor Electroanalysis III.: Oxidation of Dopamine in}

the Presence of Ascorbate

The interference of ascorbate on dopamine is well known. L-Ascorbate represents a chemically irreversible redox system with formation of dehydro-L-ascorbate in a 2electron process. ${ }^{48}$ When investigated at a $1 \mathrm{~cm}^{2}$ ITO electrode immersed into $0.1 \mathrm{mM}$ ascorbate in $0.1 \mathrm{M}$ phosphate buffer $\mathrm{pH} 7$, only an irreversible oxidation commencing at $0.2 \mathrm{~V}$ vs. $\mathrm{Ag} / \mathrm{AgCl}$ is observed for either Piranha-activated ITO or bare ITO (see Figure 7A). When the concentration of ascorbic acid is increased, the anodic signal increases accordingly consistent with ascorbate being oxidised. In the ITO-ITO dualplate electrode system the oxidation at the generator is still observed, but independent of the collector potential setting, there is no significant collector current response (see Figure 7B). The collector current signal only "shifts" according to the applied potential. That is, under these conditions ascorbate is "consumed" at the generator and not available for back-reduction independent of the choice of the collector electrode potential. 

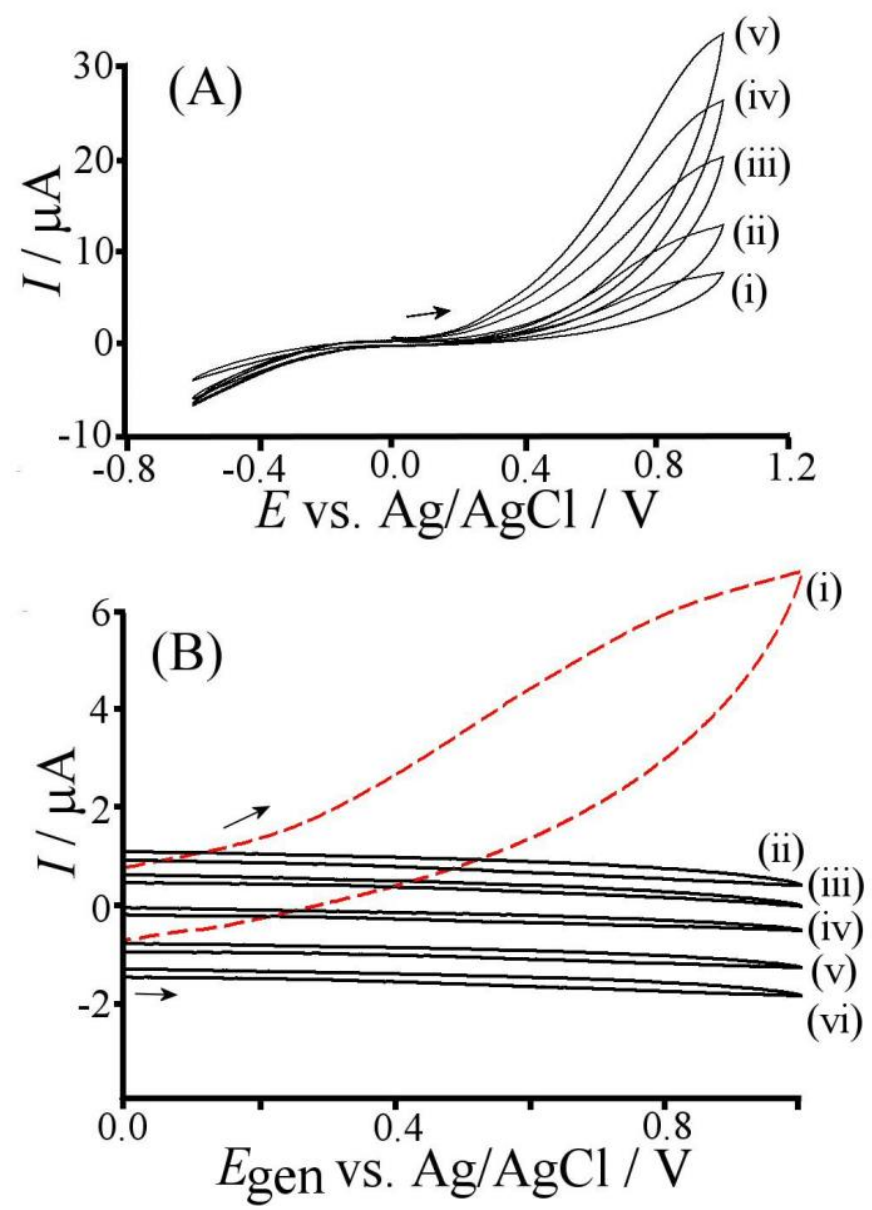

Figure 7. (A) Cyclic voltammograms (scan rate $25 \mathrm{mVs}^{-1}$ ) for ascorbate (concentration (i) 0.1 , (ii) 0.2 , (iii) 0.3 , (iv) 0.4 , and (v) $0.5 \mathrm{mM}$ in $0.1 \mathrm{M}$ phosphate buffer $\mathrm{pH}$ 7) at a $1 \mathrm{~cm}^{2}$ ITO electrode. (B) Generator-collector voltammograms (scan rate $25 \mathrm{mVs}^{-1}$ ) for $1 \mathrm{mM}$ ascorbate for an ITO-ITO dual-plate sensor with (i) generator current and (ii)-(vi) collector currents for $\mathrm{E}_{\text {collector }}=$ (ii) 0.5 , (iii) 0.25 , (iv) $0.0,(\mathrm{v})-0.25$, and (vi) $-0.5 \mathrm{~V}$ vs. $\mathrm{Ag} / \mathrm{AgCl}$.

When a combination of ascorbate and dopamine is investigated there appears to be a clear separation, with dopamine generator and collector currents relatively unaffected (see Figure 8). Changing the concentration of dopamine in the presence of ascorbate (see Figure 8A and 8B) allows reliable collector current responses to be obtained with an onset potential of ca. $0.25 \mathrm{~V}$ vs. $\mathrm{Ag} / \mathrm{AgCl}$. The ascorbate is oxidised irreversibly and therefore not adding to the feedback current. A smaller peak feature at ca. $0.6 \mathrm{~V}$ 
vs. $\mathrm{Ag} / \mathrm{AgCl}$ in both generator and collector current could be associated with the surface of the electrode being affected by either ascorbate of dopamine, but during these experiments the current signals remain stable without the need for "reactivation" of the electrode in Piranha.
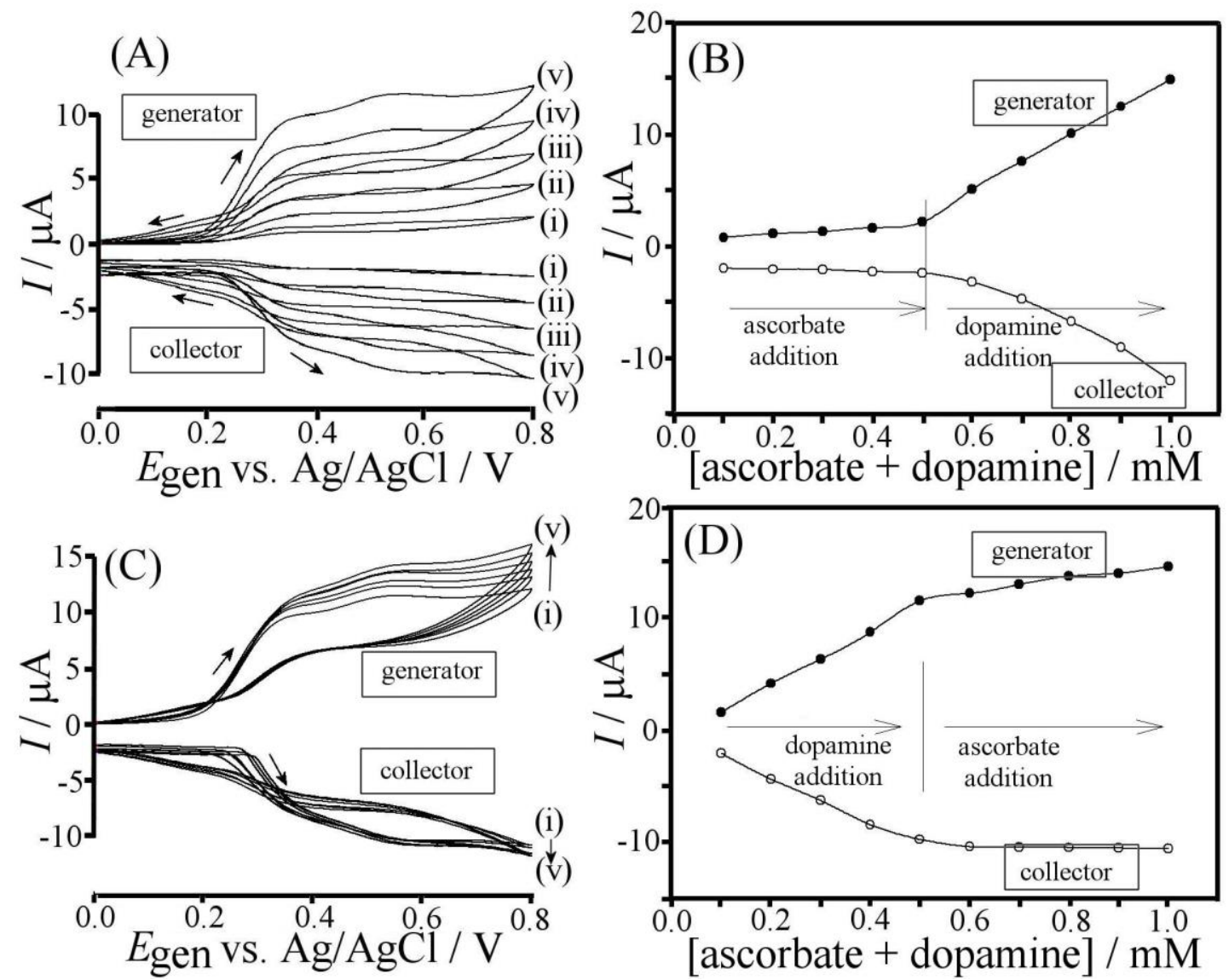

Figure 8. (A) Cyclic voltammograms (scan rate $0.025 \mathrm{Vs}^{-1}, E_{\text {collector }}=-0.5 \mathrm{~V}$ vs. $\mathrm{Ag} / \mathrm{AgCl}$ ) for a dual-plate ITO-ITO electrode immersed in $0.1 \mathrm{M}$ phosphate buffer $\mathrm{pH}$ 7 after addition of $0.5 \mathrm{mM}$ ascorbate with (i) 0.1 , (ii) 0.2 , (iii) 0.3 , (iv) 0.4 , and (v) 0.5 $\mathrm{mM}$ dopamine. (B) Plot of limiting currents versus sum of concentrations of ascorbate and dopamine. (C) As above but with addition of $0.5 \mathrm{mM}$ dopamine first then addition of (i) 0.1 , (ii) 0.2 , (iii) 0.3 , (iv) 0.4 , and (v) $0.5 \mathrm{mM}$ ascorbate. (D) Plot of limiting currents versus sum of concentrations of dopamine and ascorbate. 
A similar experiment conducted by adding $0.5 \mathrm{mM}$ dopamine first followed by stepwise addition of ascorbate gives very similar results (see Figure 8C and 8D) confirming that systematic variation in ascorbate concentration has no significant effect on the collector current response. The limiting current for the dopamine oxidation in both cases is $I_{\text {collector }}=10 \mu \mathrm{A}$, which based on equation 2 and $D_{\text {dopamine }}=$

$0.60 \times 10^{-9} \mathrm{~m}^{2} \mathrm{~s}^{-1},{ }^{49,50}$ is in excellent agreement with the anticipated two electron redox conversion of dopamine.

The use of ITO in the dual-plate electrode may have some disadvantages over traditional metal or carbon electrodes due to the sometimes sluggish electron transfer at the oxide surface as well as the tendency for adsorbate attachment. However, in conjunction with the Piranha cleaning process, the ITO-ITO dual plate trench sensor appears much more active and re-usable, at least for the case of dopamine, which is important due to the lack of polishing or other cleaning procedures for micro-trench electrodes.

\section{Conclusions}

It has been shown that dual-plate or "micro-trench" electrodes offer interesting interference screening effects which allow chemically irreversible redox systems such as oxygen and ascorbate to be "removed" in situ by pre-electrolysis at the "mouth" of the sensor electrode. This type of process is dependent on the aspect ratio of trenchwidth to trench-depth. Considerable future improvements in the observed effects are likely for "nano-trench" electrodes with smaller width. Very interesting for future 
applications will be the exploration of new types of electrodes with sub-micrometer gap, either made from ITO or from metal substrates, possibly produced based on readily available lithography technologies.

\section{Acknowledgements}

Financial support for this work and a study visit at the University of Bath was provided to Dr. Mohammad A. Hasnat by the RSC Analytical Chemistry Trust Fund(Registered Charity Number 207890). M.A.H. also acknowledges support from the research centre of Shahajalal University of Science and Technology (SUST). S.E.C.D. and F.M. thank EPSRC for support (EP/I028706/1).

\section{References}

1 N.Q. Li, J.X. Wang, M.X. Li, Rev. Anal. Chem., 2003, 22, 19-33.

2 Y. Wang, H. Xu, J.M. Zhang, G. Li, Sensors, 2008, 8, 2043-2081.

3 E. Bakker, M.E. Meyerhoff, Anal. Chim. Acta, 2000, 416, 121-137.

4 S.E.C. Dale, F. Marken, Specialist Periodical Reports, 2013, in print.

5 E.O. Barnes, G.E.M. Lewis, S.E.C. Dale, F. Marken, R.G. Compton, Analyst, 2012, 137, 1068-1081.

6 M.A.G. Zevenbergen, B.L. Wolfrum, E.D. Goluch, P.S. Singh, S.G. Lemay, J. Am. Chem. Soc., 2009, 131, 11471-11477. 
7 L. Rassaei, F. Marken, Anal. Chem., 2010, 82, 7063-7067.

8 L. Rassaei, K. Mathwig, E.D. Goluch, S.G. Lemay, J. Phys. Chem. C, 2012, 116, 10913-10916.

9 S.G. Lemay, S. Kang, K. Mathwig, P.S. Singh, Acc. Chem. Res., 2013, 46, 369-377.

10 P.S. Singh, E. Katelhon, K. Mathwig, B. Wolfrum, S.G. Lemay, ACS Nano, 2012, 6, 9662-9671.

11 A.T. Hubbard, D.G. Peters, Crit. Rev. Anal. Chem., 1973, 3, 201-242.

12 R.G. Compton, C.E. Banks, Understanding Voltammetry, World Scientific, London, 2007, 94.

13 A. Vuorema, M. Sillanpää, M. Vehviläinen, T. Kamppuri, P. Nousiainen, W. Thielemans, F. Marken, Electroanalysis, 2013, 25, 1773-1779.

14 J.H. Sluyters, Rec. Trav. Chim, , 1963, 83, 100.

15 C.R. Christensen, F.C. Anson, Anal. Chem., 1963, 35, 205.

16 L.B. Anderson, C.N. Reilley, J. Electroanal. Chem., 1965, 10, 295-305

17 A.T. Hubbard, D.G. Peters, CRC Critical Rev. Anal. Chem., 1973, 3, 201-242.

18 S.E.C. Dale, C.E. Hotchen, F. Marken, Electrochim. Acta, 2013, 101, 196-200.

19 S.E.C. Dale, Y. Chan, P.C. Bulman Page, E.O. Barnes, R.G. Compton, F. Marken, Electrophoresis, 2013, 34, 1979-1984.

20 E. Kaetelhoen, B. Hofmann, S.G. Lemay, M.A.G. Zevenbergen, A. Offenhäusser, B. Wolfrum, Anal. Chem., 2010, 82, 8502-8509.

21 M. Kullapere, J.M. Seinberg, U. Maeorg, G. Maia, D.J. Schiffrin, K. Tammeveski, Electrochim. Acta, 2009, 54, 1961-1969.

22 Q. Li, C. Batchelor-McAuley, N.S. Lawrence, R.S. Hartshorne, R.G. Compton, ChemPhysChem, 2011, 12, 1255-1257. 
23 B.M. Kile, P.L. Walsh, Z.A. McElligott, E.S. Bucher, T.S. Guillot, A.

Salahpour, M.G. Caron, R.M. Wightman, ACS Chem. Neurosci., 2012,

3, 285-292.

24 G.S. Wilson, R. Gifford, Biosens. Bioelectronics, 2005, 20, 2388-2403.

25 K. Jackowska, P. Krysinski, Anal. Bioanal. Chem., 2013, 405, 3753-3771.

26 Y.Y. Shao, J. Wang, H. Wu, J. Liu, I.A. Aksay, Y.H. Lin, Electroanalysis, 2010, 22, 1027-1036.

27 C.X. Ma, N.M. Contento, L.R. Gibson, P.W. Bohn, ACS Nano, 2013, 7, $5483-5490$.

28 A. Oleinick, F. Zhu, J.W. Yan, B.W. Mao, I. Svir, C. Amatore, ChemPhysChem, 2013, 14, 1887-1898.

29 C. Batchelor-McAuley, Q. Li, S.M. Dapin, R.G. Compton, J. Phys. Chem. B, 2010, 114, 4094-4100.

30 Q. Li, C. Batchelor-McAuley, N.S. Lawrence, R.S. Hartshorne, R.G. Compton, Chem. Commun., 2011, 47, 11426-11428.

31 Q. Li, C. Batchelor-McAuley, N.S. Lawrence, R.S. Hartshorne, R.G. Compton, ChemPhysChem, 2011, 12, 1255-1257.

32 J.M. Pero Campos-Martin, G. Blanco-Brieva, J.L.G. Fierro, Angew. Chem.Internat. Ed., 2006, 45, 6962-6984.

33 M. Amiri, S. Shahrokhian, F. Marken, Electroanalysis, 2007, 19, 1032-1038.

34 S.J. Li, J.Z. He, M.J. Zhang, R.X. Zhang, X.L. Lv, S.H. Li, H. Pang, Electrochim. Acta, 2013, 102, 58-65.

35 A. Babaei, A.R. Taheri, Sens. Actuators B-Chem., 2013, 176, 543-551.

36 K.T. Kawagoe, R.M. Wightman, Talanta, 1994, 41, 865-874. 
37 W. Sun, Y.H. Wang, Y.Y. Zhang, X.M. Ju, G.J. Li, Z.F. Sun, Anal. Chim. Acta, 2012, 751, 59-65.

38 H.X. Ju, J.G. Ni, Y. Gong, H.Y. Chen, D. Leech, Anal. Lett., 1999, 32, 2951-2964.

39 S.A. Kumar, C.F. Tang, S.M. Chen, Talanta, 2008, 74, 860-866.

40 L. Liu, J.M. Du, S.J. Li, B.Q. Yuan, H.X. Han, M. Jing, N. Xia, Biosens. \& Bioelectron., 2013, 41, 730-735.

41 A. Oleinick, F. Zhu, J.W. Yan, B.W. Mao, I. Svir, C. Amatore, ChemPhysChem, 2013, 14, 1887-1898.

42 J.R.E. Thabano, M.C. Breadmore, J.P. Hutchinson, C. Johns, P.R. Haddad, J. Chromatography, 2007, 1175, 117-126.

43 J.B. Zimmerman, R.M. Wightman, Anal. Chem., 1991, 63, 24-28.

44 M.D. Hawley, S.V. Tatawawadi, S. Piekarski, R. N. Adams, J. Chem. Soc., $1967,89,447$

45 P. Vacca, M. Petrosino, R. Chierchia, A. Guerra, C. Minarini, A. Rubino, Macromol. Symp., 2007, 247, 333-339.

46 G. Gerhardt, R.N. Adams, Anal. Chem. 1982, 54, 2618-2620.

47 R. Trouillon, Y.Q. Lin, L.J. Mellander, J.D. Keighron, A.G. Ewing, Anal. Chem. 2013, 85, 6421-6428.

48 F. Prieto, B.A. Coles, R.G. Compton, J. Phys. Chem. B, 1998, 102, 7442-7447.

49 G. Gerhardt, R.N. Adams, Anal. Chem., 1982, 54, 2618-2620.

50 E.O. Barnes, G.E.M. Lewis, S.E.C. Dale, F. Marken, R.G. Compton, J. Electroanal. Chem., 2013, 703, 38-44. 